\title{
Personality Traits and Their Validity in Predicting Job Performance at Recruitment: a Review
}

\section{O. ALHENDI}

The University of Debrecen, Faculty of Economics And Business, Ihrig Károly Doctoral School. e-mail: osamaelhindi@outlook.com

Abstract. One of the most critical challenges human resources management usually faces is the procedure of recruitment and selection. At the recruitment, the factor of qualification is very important. However, HR management should take into account the personality of the candidate. For example, most of the companies' profits rely on the performance of the frontline employee and their behavior toward the customer. Therefore, HR management usually uses the assessment of personality and integrity. Based on the literature, there is a correlation between personality traits and job performance. This study is a literature review analysis which contains previous studies in regard to the usage of Big Five Factors at the recruitment and their validity in predicting employee's performance in the firm.

Keywords: Human resources management, Big Five Factors, Job performance, Moral behavior

\section{Introduction}

In literature, there are many studies regarding the influence of HR on the company's performance. For example, Huselid and Becker (1996) made what is called HR index in order to show to which level companies with high performance reached. The study was conducted on 740 companies. As a result, firms with high scores in the HR index perform efficiently and effectively in the marketplace. In addition, Guest et al (2000) made a survey on 835 private firms. The study found out that the high usage of HR policies relating to the commitment of employee may lead to high productivity as well as high quality of the company's service. Therefore, the HR department can play an important role in influencing the performance of the firm. This impact can be analyzed depending on what the HR department is responsible for. In fact, HR is responsible for many missions such as attracting and hiring people with excellent skills, improving the workplace environment, rewarding, etc. [1].

In this paper, the focus will be on personality assessments and recruitment. In fact, recruitment is the process in which HR usually identifies and attracts prospective people from out and inside the entity in order to evaluate and finally employ them. Therefore, the process of selection usually takes place after the identification of prospective people for a specific position [2]. Furthermore, many studies indicate that there is a strong linkage between the recruitment \& selection and the firm's performance [3]. In literature, business's successful performance in the market is attributed to the people who work for the company. Simultaneously, the company's bad results are also related to the failure of the 
workplace. The reason behind that is due to the recruitment of wrong candidates or the failure to predict volatility in the needs of recruitment. Therefore, it could be a difficult mission to select the right candidate. Depending on that, the reputation of the organizations can be affected by the employee they hire [4]. In this regard, human resources management should take into the account not just the qualification but also they should focus on other additional considerations such as integrity and personality factors especially in the companies (such as banks, insurance companies, telecommunication companies, etc.) which rely heavily on their frontline employees team. In previous years, many studies gave careful attention to the importance of frontline employee's moral behavior. These studies tried to analyze the impact of frontline employee's moral behavior in enhancing relationships with the company's clients. For example, Kelley and Hoffman (1997) analyzed the impact of prosocial behaviors (in which positive behavior enhances social acceptance and friendship) [5]. Another study focused on listening behaviors such as the study of de Ruyter and Wetzels (2000) [6]. Furthermore, the relationship with clients could normally be developed and enhanced in the long term through the ethical behavior of sales team members or frontline employees of the company [7]. On the other hand, unethical sales behavior is a short-term frontline employee's behavior which enables him or her to earn at the account of the client. Unethical behaviour may include activities aiming to mislead the customer form the reality such as the tendency to not telling the truth or to represent the service or product as being better than it really is, high pressure on the customer to buy, providing the customers with answers when the answers are not known, etc. [8][9]. These activities may negatively influence the company's reputation.

Besides that, moral sales behavior has effect on each of trust, satisfaction and the loyalty of customers. For example, each of Roman and Ruiz (2005) and Lagace et al. (1991) attributed customer's satisfaction to ethical sales behavior of the employees [10][9]. In the case of customer's trust, each of Swan et al. (1988) and Alrubaiee (2012) proved that the customer's trust is resulted from the honesty of sales employees [11][12]. In addition, the customer's trust leads to customer's loyalty [12].

In fact, the moral behavior of the candidates should be considered at the phase of the recruitment. To do so, HR management should evaluate the candidates using integrity and personality assessments. In this study, the aim is to analyze, through the literature, the predictive ability of Big Five Factors model (which is considered one of the most popular models in assessing the personality of the candidates) and whether this model can be an optimal measure for the personality of the candidate or not according to the literature.

\section{Methodology}

This study used a literature review analysis about the ability of personality traits in predicting the performance of the employee in the company. The study gave careful attention to the role of the Big Five Factors and their predictive validity according to the literature. Therefore, the review included analysis about the previous scientific works which were done by scholars and a number of critiques regarding each factor and its validity. 


\section{Personality assessment besides GMA test in predicting job performance}

It is possible to predict occupational performance through a number of tests by which the company can decide to hire the employee or not. The most important occupational performance predictor is called General Mental Ability (GMA). GMA is very helpful for employers because it enables them to choose among the candidates very easily. On other words, people who got a higher score in the GMA test are able to perform well in the position. The reason behind that they can be familiar quickly and deeply about the job faster than others with a low score in the GMA test. In addition, GMA test is valid predictor for different types of jobs as well as job performance. However, there are also other methods that can be effective in predicting the performance of the job such as biographical test, integrity test, the test of job knowledge, peer ratings, unstructured or structured interviews [13]. Moreover, it could be a good decision to use a combination of different methods in order to predict the occupational performance and decrease the risk of hiring. It is necessary to add here that the predictive validity of the GMA test equals 50\%. Therefore, adding a new method to GMA test may increase the ability to predict. For example, suppose that HR management uses GMA test plus integrity test. As a result, this combination can provide a higher ability to predict job performance than other combinations such as GMA test plus a structured interview and GMA and an unstructured interview respectively. This kind of combinations in which additional methods could be added to GMA test in order to provide extra necessary information about the job performance is called incremental validity [13]. On other words, the integrity test increases GMA's predictive ability by about $20 \%$. In relation to structured and unstructured interviews, the ability of GMA to predict is increased by $18 \%$ and $13 \%$ respectively. Comparing to the rest of other methods, job interests evaluation is the only method which adds up to $10 \%$ to GMA's predictive ability. Therefore, the combination of GMA test and integrity test adds the highest amount in percent to the predictive validity at the recruitment process [13].

According to the previous paragraph, the integrity test adds the highest incremental validity to GMA test. In fact, the integrity test is divided into the following. The first one is called direct evaluation in which the employer may directly ask the respondents about their attitudes toward dishonesty and their opinions about that. In addition, they may ask the respondents to talk about their past dishonest experiences. The second part of the integrity test is called an indirect evaluation. In indirect evaluation, the aim is to determine and analyze the aspects of the respondent's personality in terms of their internal character whether dishonest behavior is situated under it or not. However, personality evaluation can be far for the destination and truth. To be more precise, the respondents have the chance to be less clear and transparent and able to distort their answers. Despite their association to a person's behavior, direct method's validity is slightly higher than that of an indirect method [14].

\section{Big Five Factors Model and its predictive validity}

In fact, personality assessment has a close relation to the test of integrity and also helps to predict job performance. One of the most popular models which reflects the human's personality traits is called Big Five Factors. The Big Five Factors includes conscientiousness, openness to experience, 
extraversion, agreeableness, and emotional stability. In terms of their predictive ability, each of conscientiousness and emotional stability has a moderate ability to predict the performance of the job. By adding the GMA test, these factors tend to be zero except conscientiousness and openness to experience respectively [13].

In the beginning, each factor has its own meaning and importance in expecting occupational performance at the recruitment. Firstly, conscientiousness is defined as the tendency which is resulted from a person's inside to be more committed and to think wisely before taking the action [15]. Having a high sense of conscientiousness means that the person is more reliable, trusted, high tendency to make achievement [16]. In order to examine its predictive validity, Schneider (1999) investigated the relationship between conscientiousness and the satisfaction factor in many careers and found out that there is a strong relationship between them [17]. Furthermore, Maertz and Griffeth (2004) indicated that having high conscientiousness may lead the employee planning to leave the job to ask himself/herself whether him/her leave can influence the performance of the company or not or whether he/she has a responsibility toward their company or not [18]. Secondly, openness to experience focuses on a person's mind and his/her capability to imagine and to be cultural, curious and open [19]. For example, Cohrs et al., (2006) found out that the factor of openness to experience leads to the job satisfaction of the teachers of mathematics [20]. In addition, Schneider (1999) emphasized that the relationship between different constructs of personality and job satisfaction differs relying on on job setting [17]. In addition, there is an association between openness to experience and the satisfaction among several employees like co-workers in the company as well as job in general in the job description. However, regardless of the four aspects of Big Five Factors, openness to experience is not strongly correlated to the job satisfaction [21]. Thirdly, extraversion is the feeling by which the individual can be more positive and excited. Therefore, the extrovert is likely to be more positive and able to make strong relations with other people. Therefore, extraversion can be a good indicator and predictor for physical or mental collapse which can be caused by stress and overloaded work [22]. As a result, it could be logical to conclude that extroversion can lead to job satisfaction due to the positive mindset of the extroverts [23]. Fourthly, agreeableness measures to what extent the person can be flexible and tolerant plus the ability to forgive and cooperate [19]. Consequently, Judge et al., (1999) found out that agreeableness can be a valid forecaster for the performance of employees working in a team [24]. These results are also backed by the study of Neuman and Wright (1999) [25]. Finally, emotional stability is defined as a measurement of each degree of anxiety, the feelings of depression and anger and the status of instability [19]. In other words, an individual with high neuroticism can be dissatisfied or neuroticism can be considered as a predictor for job dissatisfaction [26].

In the literature, many studies shed light on the linkage between the Big Five Factors and job performance. According to Judge et al. (2002), Big Five Factors has impact on job performance. For example, each of extraversion, conscientiousness, and agreeableness has a positive correlation with job performance. On the contrary, neuroticism negatively influences job performance. In the case of openness to experience, its impact on job performance is small or not significant [21]. 
In fact, the presence of the Big Five Factors led the scholars to make meta-analysis reviews regarding the predictive ability of the personality [19]. In addition, the most famous instrument or approach which can be used in order to analyze the personality is the Big Five Factors [27]. These factors reflect the differences in the personality of people. Most of the studies tried to investigate the predictive ability or the validity of these factors in predicting the performance in the company. Furthermore, according to meta-analysis reviews, the predictive ability of some factors of the model can work regardless of the position announced through the company such as conscientiousness. For example, in order to predict the success of training in the company, the research indicated that the differences in personality in terms of conscientiousness, extraversion, and openness to experience provide a prediction about the validity of the training. In the case of conscientiousness, it was found out that this factor is a good forecaster in terms of career and the performance [19]. In addition, each of agreeableness, extraversion, and openness to experience are considered as good forecasters for each of particular careers and standards [28]. In the following paragraphs, the paper shows a number of previous studies in respect of the impact of personality on the job performance.

In 1998, Barrick et al., examined the correlation between the personality facets and job performance in jobs which entails interpersonal communication or reciprocal action between employees. Using the P-value statistical approach, the P-value for each of the following factors show that there could be a relationship. For example, each of conscientiousness, agreeableness and emotional stability has Pvalue equalling to (0.26), $(0.21)$ and (0.18) respectively which in turn means that they have a relationship with job performance [29]. In 2001, Barrick and Mount investigated and revised further about the linkage between personality and job performance. According to the meta-analysis of Barrick et al. (2001), the researchers made an investigation on 15 meta-analysis reviews and on the quantitative way. As a result, the outcomes of their investigation were as the following. Using the Pvalue approach, conscientiousness's P-value equals to (0.27) which means that there is a relationship to the performance. In the case of extraversion and agreeableness, both of them has the same value (0.13) which indicated that there is to some extent a relationship to the performance. Whereas openness to experience and emotional stability (where their P-value equal to (0.03) and (0.09) respectively) have a weak relation to the performance [30].

Furthemore, Vinchur et al., (1998) investigated the influence of the Big Five Factors on the sales performance in the companies. In terms of the predictive ability for each factor, (r) value of conscientiousness as well as extraversion equals to (0.17) and (0.12) respectively. On the other side, each of agreeableness and emotional stability has a negative relation to the sales performance of the company [31]. These findings are also similar to the results of Salgado (1997) in which conscientiousness, extraversion, and emotional stability equal (0.10), (0.05) and (0.09) respectively [32]. In 1998, Salgado got the same results where conscientiousness, extraversion, and emotional stability equal (0.13), (0.10) and (0.15) in the order [33].

In addition, Hurtz and Donovan (2000) investigated whether there is a correlation between the personality and each of job and training performance. According to their meta-analysis review, the statistical method used in their study is called true score approach in which conscientiousness with (0.24) followed by emotional stability and agreeableness with (0.15) and (0.12) respectively. On the 
other words, conscientiousness has high ability to predict the performance in comparison to other factors[34].

Trapmann et al., (2007) made an investigation which was about the linkage between the Big Five Factors and the training performance. According to the study's results, conscientiousness's mean ( $r$ ) value equals to $(0.216)$ which means that it has a strong relation to the performance. The same results can be with respect to openness to experience and agreeableness (by (0.083) and (0.041) respectively). Similarly, the study about the correlation between Big Five Factors and organizational citizenship behavior (OCB) is similar to that with the performance. Moreover, conscientiousness, openness to experience, agreeableness, and emotional stability are strongly related to the OCB in the order (by (0.14), (0.11), (0.11) and (0.10) respectively). Depending on these results, it is obvious that the correlation between personality and OCB is higher than that with the performance [35].

Despite the importance of the Big Five Factors model in predicting job performance, it is still subject to a number of critiques. Over the last years, the selection of candidates has given significant attention to the Big Five Factors model. Despite its popularity, the tendency for adding new dimensions into the Big Five Factors model is proved in the literature [36]. For example, in order to predict the occupational performance, Hough (1992) added each of masculinity as well as the locus of control into the constructs [37]. Nevertheless, Ones and Viswesvaran (1996) supported the usage of the model and they argued that the criteria of occupational performance are wide scope constructs [38]. In addition, each of Ozer and Reise (1994) indicated that there is a missing factor which should exist in the model. This factor is self-control which can be important for the workplace environment [39]. In fact, the usage of only five factors can limit the predictive validity according to Hogan et al., 1996 as well as Mershon \& Gorsuch, 1988 [40][41]. Furthermore, adding new particular dimensions into the model can increase the predictive validity of the occupational performance [42].

In many studies, the Big Five Factors were proved by the scholars that they aren't, to some extent, an optimal measurement for the personality. For example, Saucier and Goldberg ( 2001) found out that there are a number of difficulties relating to the usage of the Big Five Factors model [43]. Furthemore, Paunonan and Jackson (2000) indicated that there are many dimensions that can be part of Big Five Factors model such as honesty, thriftiness, sensuality, masculinity-femininity, conservativeness, deceptiveness, conceit, religiosity and humorousness [44].

In fact, the personality dimensions such as extraversion, neuroticism, and psychoticism were added to the Eysenck Questionnaire and also its edited version. According to Eysenck (1991, 1992) [45][46], the criteria for the acceptance of the Big Five Factors model (which were reported by Costa and McCrae) were not sufficient for identifying the personality's dimensions. Eysenck also pointed out that each of agreeableness and conscientiousness is fundamental traits of the revised Eysenck Personality Questionnaire, Psychoticism factor. However, it is probably that Eysenck personality factors such as extraversion, neuroticism, and psychoticism, as well as big five factors, provide different layers of descriptions about the personality traits which are arranged on the hierarchical basis [47]. In addition, the personality structure of the Big Five Factors appears only among people who have received formal education. Therefore, it raises the doubt around the soundness of the Big Five Factors model [48]. 
Despite the popular status Big Five Factors have got through the last years, their validity as one construct is questionable and under the doubt by many researchers such as Block, (1995), Boyle et al., (1995); Cattell, (1995) [49][50][51].

For example, Block (1995) developed two critiques by which it was not the end of the Big Five Factors but to further raise the scientific competition for the prevailing model of personality construct. Block and his wife (Jeanne Block) have derived two broad dimensions of personality from a wide range of different psychodynamic suggestions and proposals in 1995. These two dimensions are ego-resiliency and ego-control. In fact, Block followed a tactic in defending his claim by attacking others' models. On the other words, he claimed that Big Five Factors are confuted but there is no real alternative to present. Moreover, Block temporarily suggested six dimensions as a model starting with his two broad previously-mentioned dimensions. Block's temporarily-proposed model includes ego control, ego resiliency, agency-communion, introspectiveness, liberalism-conservatism, and energy level (Block, 1995). Over the last fifteen years, this taxonomy has got accumulated support from a strong program of research. In addition, it was proved that this taxonomy has superiority comparing to that in the case of the Big Five Factors. Considering the detailed explanation and factor analyses (using Q-sort) of Block in 1995 and 2010, all his documented work clearly supported his model. According to his factor analysis using 100-item Q-sort, twenty reliable factors were discovered. Moreover, Block's Q-sort analysis has not supported the Big Five Factors. Yet, Block neither issued this analysis nor allowed others to do that. Depending on the last paragraphs, it could be expectable that Big Five Factors will be subjected to be substituted by a better and more detailed structure for research on personality in the future [52].

\section{Conclusions}

Despite the importance of the Big Five Factors model in predicting job performance, it has been criticized by many researchers. In addition, the model is broad and unable to provide an accurate prediction. Furthermore, it is not an optimal measurement of the performance. Besides that, the static trait is attributed to the model. In other words, the model should be modified or replaced to be more dynamic in relation to the structure of the personality. Therefore, future studies should find an optimal dynamic model which can be reflective for the personality of the candidate as well as to be useful and helpful at the recruitment. This, in turn, can make the process of recruitment more effective and critical, predicting the performance of the employee in a better way and increase the loyalty and trust of the client to the company especially for the companies relying on sales team members.

\section{References}

[1] Michael Armstrong (2006) Strategic Human Resource Management : A Guide to Action. Kogan Page. London. p. 73-74.

[2] Walker, James (2009) Human Resource Planning, New York: McGraw-Hill Book Co., P-95.

[3] Gamage, A. S. (2014) Recruitment and selection practices in manufacturing SMEs in Japan: An analysis of the link with business performance. Ruhuna Journal of Management and Finance, 1(1), $37-52$ 
[4] Henry, O., \& Temtime, Z. (2009) Recruitment and selection practices in SMEs: Empirical evidence from a developing country perspective. Advances in Management, 3(2), 52-58.

[5] Kelley, S.W. and Hoffman, K.D. (1997) "An Investigation of Positive Affect, Prosocial Behaviors and Service Quality", Journal of Retailing, 73, pp.407- 427.

[6] De Ruyter, K. and Wetzels, M.G.M. (2000) "The Impact of Perceived Listening Behavior in Voiceto-Voice Service Encounters", Journal of Service Research, 2, 3, pp.276-284.

[7] Wray, B., Palmer, A. and Bejou, D. (1994) "Using Neural Network Analysis to Evaluate Buyer-Seller Relationships", European Journal of Marketing, 28, 10, pp.32-48.

[8] Hoffman, K.D., Howe, V. and Hardigree, D.W. (1991) "Ethical Dilemmas Faced in the Selling of Complex Services: Significant Others and Competitve Pressures", Journal of Personal Selling and Sales Management, 11, (Fall), pp.13-25.

[9] Lagace, R.R., Dahlstrom, R. and Gassenheimer, J.B. (1991) "The Relevance of Ethical Salesperson Behavior on Relationship Quality: The Pharmaceutical Industry", Journal of Personal Selling and Sales Management, 11, Fall, pp.39- 47

[10] Roman S and Ruiz S (2005) Relationship outcomes of perceived ethical sales behavior:The customers perspective. J. Business.Research 58:439-445.

[11] Swan, J.E., Trawick, Jr.I.F., Rink, D.R., Roberts, J.J (1988) Measuring Dimensions of Purchaser Trust of industrial Salespeople. Journal Personal Selling and Sales Management, 8(2), 1-9.

[12] Alrubaiee, L. (2012) Exploring the Relationship between Ethical Sales Behavior, Relationship Quality and Customer Loyalty. International Journal of Marketing Studies, 4(1), 7-25.

[13] Davies W. - Mcdonald A. (2018) Predicting job performance at recruitment. Pearson TalentLens. https://www.talentlens.co.uk/wp-content/uploads/sites/5/White-Paper-The-Science-BehindPredicting-Job-Performance-at-Recruitment.pdf , accessed: 17.04.2019.

[14] Van Iddekinge, C. H., Roth, P. L., Raymark, P. H. and Odle-Dusseau, H. N. (2012) The criterionrelated validity of integrity tests: An updated meta-analysis. Journal of Applied Psychology, 97, 499-530.

[15] Cook, M. (2004) Personnel selection: Adding value through people. Fourth edition Chichester: John Wiley \& Sons

[16] Barrick, M. R., Mount, M. K. (1993) Autonomy as a moderator of the relationships between the Big Five personality dimensions and job performance. Journal of Applied Psychology. 78 (1). pp. 111118. DOI: $10.1037 / / 0021-9010.78 .1 .111$

[17] Schnedier, M. H. (1999) The relationship of personality and job settings to job satisfaction. Dissertation Abstracts International: Section B: Science and Engineering. 59. 6103.

[18] Maertz, C. P. Jr., Griffeth, R. W. (2004) Eight Motivational Forces and Voluntary Turnover :A Theoretical Synthesis with Implications for Research. Journal of Management. 30 (5). pp. 667683. DOI: 10.1016/j.jm.2004.04.001

[19] Barrick, M. R., \& Mount, M. K. (1991) The Big Five personality dimensions and job performance. Personnel Psychology, 44, 1-26.

[20] Cohrs, C. J., Abele, A. E., Dette, D. E. (2006) Integrating Situational and Dispositional Determinants of Job Satisfaction: Findings From Three Samples of Professionals. The Journal of Psychology. 140 (4). pp. 363-395. DOI: 10.3200/JRLP.140.4.363-395

[21] Judge, T. A., Ilies, R. (2002) Relationship of personality to performance motivation: A metaanalytic review. Journal of Applied Psychology. 87 (4). pp. 797-807. DOI: 10.1037//00219010.87.4.797 
[22] Bakker, A. B., Van Der Zee, K. I., Lewig, K. A., Dollard, M. F. (2006) The relationship between the Big-Five personality factors and burnout : A study among volunteer counselors. The Journal of Social Psychology. 146 (1). pp. 31-50. DOI: 10.3200/socp.146.1.31-50

[23] Connolly, J. J., Viswesvaran, C. (2000) The role of affectivity in job satisfaction: A meta-analysis. Personality and Individual Differences. 29 (2). pp. 265-281. DOI: 10.1016/s01918869(99)00192-0

[24] Judge, T. A., Higgins, C. A., Thoresen, C. J., Barrick, M. R. (1999) The Big Five Personality Traits, General Mental Ability, and Career Success across the Life Span. Personnel Psychology. 52 (3). pp. 621-652 DOI: 10.1111/j.1744-6570.1999.tb00174.x

[25] Neuman, G. A., Wright, J. (1999) Team effectiveness: beyond skills and cognitive ability. Journal of Applied Psychology. 84 (3). pp. 376-89. DOI: 10.1037//0021-9010.84.3.376

[26] Clark, L. A., Watson, D. (1991) General affective dispositions in physical and psychological health. In: Snyder, C. R., Forsyth, D. R. (eds.) Handbook of social and clinical psychology: The health perspective. New York: Pergamon.

[27] Goldberg LR (1990). An Alternative Description of Personality: The BigFive Factor structure. J. Pers. Soc. Psychol., 59(6): 1216-1229.

[28] Barrick, M. R., \& Mount, M. K. (2005): Yes, Personality Matters: moving on to more important matters. Human Performance, 18(4), 359-372.

[29] Barrick, M. R., Stewart, G. J., Neubert, M. J., \& Mount, M. K. (1998). Relating member ability and personality to work-team processes and team effectiveness. Journal of AppliedPsychology, 83(3), 377-391.

[30] Barrick, M. R., Mount, M. K., \& Judge, T. A. (2001), Personality and Performance at the beginning of the new millennium: what do we know and where do we go next? International journal of slection and assessment, 9(1/2), 9-30. http://doi.org/10.1111/1468-2389.00160

[31] Vinchur, A. I., Schippmann, J. S. Switzer, F. S. , \& Roth, P. L. (1998), A meta-analytic review of predictors of job perfromance of salespeople. Journal of Applied Psychology, 83, 586-597.

[32] Salgado, J. F. (1997), The five factor model of personality and job performance in the European community. Journal of Applied Psychology, 82(1), 30-43. http://doi.org/10.1037/00219010.82.1.30

[33] Salgado, J. F. (1998) Big five personality dimensions and job performance in army and civil occupations: A European perspective. Human Performance, 11(2-3), 271-288.

[34] Hurtz, G. M., \& Donovan, J. J. (2000) Personality and Job performance: The big five revisited. Journal of Applied Psychology, 85(6), 869-879.

[35] Trapmann, S., Hell, B., Hirn, J. W., \& Schulder, H. (2007) Meta-Analysis of the relationship between the big five and academic success at university. Journal pf Psychology. 215(2), 132-151. doi: 10.1027/0044-3409.215.2.132.

[36] Hogan, J., \& Roberts, B. W. (1996) Issues and non-issues in the fidelity-bandwidth trade-off. Journal of Organizational Behavior, 17, 627-637.

[37] Hough, L. M. (1992) The Big Five personality variables-construct confusion: Description versus prediction. Human Performance, 5, 139-155.

[38] Ones, D. S., \& Viswesvaran, C. (1996) Bandwidth-fidelity dilemma in personality measurement for personnel selection. Journal of Organizational Behavior, 17, 609- 626.

[39] Ozer, D. J., \& Reise, S. P. (1994) Personality assessment. Annual Review of Psychology, 45, 357-388. 
[40] Hogan, R., Hogan, J., \& Roberts, B. W. (1996) Personality measurement and employment decisions. American Psychologist, 51, 469-477.

[41] Mershon, B., \& Gorsuch, R. L. (1988) Number of factors in the personality sphere: Does increase in factors increase predictability of real-life criteria? Journal of Personality and Social Psychology, $55,675-680$.

[42] Schneider, R. J., Hough, L. M., \& Dunnette, M. D. (1996) Broadsided by broad traits: How to sink science in five dimensions or less. Journal of Organizational Behavior, 17, 639-655.

[43] Saucier, G., \& Goldberg, L. R. (2001) Lexical studies of indigenous personality factors: premises, products and prospects. Journal of Personality, 69, 847-879.

[44] Paunonen S. V., \& Jackson, D. N. (2000) What is beyond the Big Five? Plenty! Journal of Personality, 68, 821-835.

[45] Eysenck, H. J. (1991) Dimensions of personality: 16, 5, 3?: Criteria for a taxonomic paradigm. Personality and Individual Differences, 12, 773-790.

[46] Eysenck, H. J. (1992) Four ways five factors are not basic. Personality and Individual Differences, 13, 667-673.

[47] Boyle, G. J. (1989) Re-examination of the major personality-type factors in the Cattell, Comrey, and Eysenck scales: Were the factor solutions by Noller et al. optimal? Personality and Individual Differences, 10, 1289-1299.

[48] Roberts, B. W., Walton, K. E., \& Viechtbauer, W. (2006) Personality traits change in adulthood: Reply to Costa and McCrae (2006). Psychological Bulletin, 132, 29-32.

[49] Block, J. (1995) A contrarian view of the five-factor approach to personality description. Psychological Bulletin, 117, 187-229.

[50] Boyle, G. J., Stankov, L., \& Cattell, R. B. (1995) Measurement and statistical models in the study of personality and intelligence. In D. H. Saklofske \& M. Zeidner (Eds.), International handbook of personality and intelligence (pp. 417-446). New York: Plenum.

[51] Cattell, H. E. P. (1995) Some comments on a factor analysis of the 16PF and NEO Personality Inventory - Revised. Psychological Reports, 77, 1307-1311.

[52] Oliver P. John \& Laura P. Naumann (2010) Surviving Two Critiques by Block? The Resilient Big Five Have Emerged as the Paradigm for Personality Trait Psychology, Psychological Inquiry: An International Journal for the Advancement of Psychological Theory, 21:1, 44-49, DOI: $10.1080 / 10478401003648732$ 